\title{
Proposta de Tipologia sobre Alianças Estratégicas
}

\author{
Vasco Eiriz
}

\section{RESUMO}

Este artigo considera as alianças estratégicas como forma particular de cooperação empresarial, reconhece a necessidade de esclarecer o conceito e sugere elementos de distinção de outras formas de cooperação e relacionamento interorganizacional. Contribuindo para este esforço de esclarecimento, reconhecem-se e discutem-se limitações na literatura, e propõe-se uma tipologia de alianças estratégicas. A tipologia adoptada é baseada em três domínios de cooperação, os quais, por sua vez, podem ser analisados à luz de várias actividades. No estudo empírico da tipologia de alianças estratégicas proposta recorreu-se a um questionário a que responderam 133 empresas industriais portuguesas participantes no programa Europartenariat da União Europeia. Os principais resultados obtidos sugerem que: (1) as empresas estudadas apresentam indicadores de cooperação muito positivos; (2) a intensidade de alianças estratégicas está associada à dimensão das empresas; (3) a intensidade global de alianças estratégicas varia consoante o sector de actividade; (4) a importância de cada tipo de aliança estratégica é também variável por sector de actividade; (5) a importância de cada tipo de aliança estratégica é variável, consoante o tipo de parceiro envolvido do outro lado da relação.

Palavras-chaves: alianças estratégicas; cooperação empresarial; parcerias estratégicas; relações interorganizacionais.

\begin{abstract}
This article assumes that strategic alliances are a particular form of co-operation between firms, recognises the need to clarify the concept, and suggests elements of distinction with other forms of co-operation and inter-organizational relationships. Contributing for this effort of clarification, the article discusses and recognises some limitations in the literature on types of strategic alliances, and proposes a new typology of strategic alliances. The typology is based on three domains of cooperation which, in turn, are based on different activities. The empirical study was based on a survey to which replied 133 Portuguese industrial firms which participated in the European Union's Europartenariat programme. The main results of this study suggest that: (1) the studied firms have very positive indicators of co-operation; (2) the intensity of strategic alliances is associated with the firms' size; (3) the global intensity of strategic alliances varies according to each industry; (4) the importance of each type of strategic alliance varies according to each industry; (5) the importance of each type of strategic alliance varies according to the type of partner involved in the other side of the relationship.
\end{abstract}

Key words: strategic alliances; co-operation between firms; strategic partnerships; interorganizational relationships. 


\section{INTRODUÇĀO}

O fenómeno da cooperação entre empresas tem despertado grande interesse na comunidade académica e nos meios empresariais, circunstância que é visível na popularidade crescente das alianças estratégicas. As alianças estratégicas ou outras formas de cooperação parecem, cada vez mais, ser uma opção recorrente, situação que acaba por se reflectir num número cada vez maior de estudos sobre o tema. Reconhecendo este facto, o objectivo deste artigo é propor uma tipologia de alianças estratégicas e analisar os domínios de cooperação e tipos de alianças desenvolvidas por uma amostra de empresas industriais.

Esta pesquisa teve como hipótese de partida que as empresas não só desenvolvem alianças estratégicas com diferentes graus de intensidade, como também as alianças em que se envolvem apresentam diferentes características. Por isso, afim de melhor compreender a actividade de cooperação interorganizacional irá propor-se uma tipologia de alianças estratégicas estruturada por três domínios de cooperação. Relativamente a esta tipologia, interessa verificar a intensidade com que as empresas recorrem a cada tipo de aliança estratégica. Interessará ainda verificar se os perfis de cooperação são substancialmente diferentes quando consideradas separadamente as alianças estratégicas com fornecedores, clientes e empresas colocadas na mesma fase do seu sistema de negócios.

Reconhecendo alguma ambiguidade de terminologia, o artigo começa por definir o conceito de aliança estratégica. Na secção 3 é revista a literatura sobre tipos de alianças estratégicas. De seguida, a secção 4 baseia-se no critério das actividades para propor uma tipologia de alianças estratégicas estruturada por três domínios de cooperação. Posteriormente, apresenta-se a metodologia que serviu de base ao estudo empírico em empresas industriais portuguesas. Na secção 6 e secção 7 são discutidos os resultados empíricos daquele estudo. Finalmente, conclui-se com a discussão das principais limitações da pesquisa e sugestão de pistas para futuros trabalhos de investigação sobre o tema.

\section{Conceito de Aliança Estratégica}

A literatura é consensual em reconhecer que uma aliança estratégica ocorre quando duas ou mais organizações decidem conjugar esforços para perseguir um objectivo estratégico comum (e.g. Johanson e Mattsson, 1988; Aaker, 1995). 
Quando assim é, os parceiros procuram desenvolver uma vantagem cooperativa que tenha efeitos positivos sobre o seu desempenho individual e colectivo.

Contudo, relações de cooperação e alianças estratégicas são, freqüentemente, sinónimos para uma mesma realidade. Existem, de facto, diferentes formas de organização da actividade económica que variam entre transações em mercado aberto ou integração das actividades numa hierarquia (Williamson, 1975, 1985). Nesta perspectiva, as relações de cooperação e alianças estratégicas podem assumir diferentes graus de integração ao longo de uma recta em que num do extremos se encontram os mercados e no outro extremo as hierarquias. Quando o mercado é a forma de organização predominante, não há integração absoluta das actividades das empresas e o preço é o mecanismo coordenador da actividade económica. No caso oposto há completa integração de actividades e o mecanismo coordenador passa a ser um processo administrativo entre unidades internas da hierarquia. Quer isto dizer que ao longo dessa recta uma aliança estratégica pode assumir, por exemplo, na proximidade dos mercados, a forma de um acordo de cooperação informal ou, mais próximo ainda do extremo da recta, um simples relacionamento comercial. No outro extremo da recta, nos limites da hierarquia, um dos parceiros pode adquirir uma participação no capital do outro, proceder a uma aquisição ou, mais próximo ainda da hierarquia, pode enveredar por uma fusão (Thorelli, 1986; Lorange e Roos, 1993). Nesta visão da forma como as empresas se podem relacionar não existe uma verdadeira distinção teórica entre uma relação de cooperação e uma aliança estratégica. Ou seja, como se afirmou anteriormente, relações de cooperação e alianças estratégicas são diferentes nomes para uma mesma realidade.

No entanto, no entender de outros autores (e.g. Faulkner, 1992), uma aliança estratégica é uma forma de organização das actividades dos parceiros que envolve um maior grau de integração do que outras formas de cooperação. Nesta perspectiva, uma aliança estratégica estaria mais próxima das hierarquias do que outras formas de relacionamento interorganizacional como, por exemplo, acordos de cooperação não estratégicos.

No entendimento adoptado neste artigo, o problema não é tanto o de posicionar o conceito de aliança estratégica ao longo duma recta, mas sim o de verificar o que verdadeiramente distingue uma aliança estratégica de outras formas de relacionamento e cooperação e, em particular, de alianças não estratégicas ou operacionais. Baseando-nos na distinção entre decisões estratégicas e decisões operacionais (Hax e Majluf, 1988; Johnson e Scholes, 1999), entende-se que as diferenças entre uma aliança estratégica e outros tipos de alianças residem fundamentalmente no facto das primeiras reunirem um conjunto de características que lhes conferem uma dimensão estratégica que não está presente nas segundas. Essas características são as seguintes: (1) uma aliança estratégica resulta de 
um conjunto coerente de decisões; (2) é um meio para desenvolver uma vantagem competitiva sustentável; (3) tem um impacto organizacional de longo prazo; (4) é um meio para responder a oportunidades e ameaças externas; (5) é baseada em recursos organizacionais que mostram forças e fraquezas; (6) afecta decisões operacionais; (7) envolve todos os níveis hierárquicos da organização; (8) é influenciada pelo seu contexto cultural e político; e (9) envolve, directa ou indirectamente, todas as actividades da organização.

Há assim várias características numa aliança que quando se verificam de forma simultânea fazem com que ela se torne estratégica. Apesar da leitura atenta dessas características mostrar que elas são fundamentais, vale ainda a pena salientar que a distinção entre alianças estratégicas e alianças operacionais não é uma variável binária e, como tal, na prática dos negócios, a natureza das alianças nem sempre é clara, circunstância que acaba por reconhecer alguma validade a modelos como o da recta que anteriormente mencionámos. Significa isto que pode haver alianças que são constituídas com objectivos estratégicos mas que acabam por se revelar menos importantes do que o previsto. No sentido oposto, há também alianças operacionais, por exemplo para gerir problemas logísticos, que com o evoluir do tempo e com a sedimentação da relação entre empresas, acabam por adquirir uma dimensão estratégia. Não menos importante é o facto de que, por vezes, quando os parceiros não comunicam claramente entre si os propósitos e objectivos que os motivam, para alguns uma aliança pode ser estratégica, enquanto que para os seus parceiros a mesma aliança pode ter um papel meramente operacional.

\section{Tipos de Alianças Estratégicas}

São imensos os tipos de alianças estratégicas apresentadas na literatura. Por exemplo, Aaker (1995) destaca o grau de formalização dos acordos para concluir que as alianças podem assumir diversas formas, desde acordos informais até uma joint venture formal. A distinção entre estratégias de cooperação formais e informais tem, aliás, merecido bastante destaque na literatura (e.g. Håkansson e Johanson, 1988).

Douglas e Craig (1995) apresentam três formas de colaboração entre concorrentes que têm por base as fases da cadeia de valor dos cooperantes. Assim, é possível distinguir entre projectos de colaboração para investigação e desenvolvimento de novos produtos, colaboração na produção e logística e colaboração no marketing e distribuição. 
Faulkner (1992) apresenta três dimensões de classificação das alianças estratégicas e, em função das diferentes conjugações dessas dimensões, extrai oito opções. Na primeira dimensão (focalizada versus complexa), o autor socorrese das actividades desenvolvidas pelos parceiros; a segunda dimensão (joint venture versus non-joint venture) respeita ao capital e forma jurídica da aliança; na terceira dimensão (dois parceiros versus consórcio) sobressai o número de parceiros envolvidos. Por seu lado, Root (1988) utiliza duas dimensões distintas das anteriores para classificar os acordos de cooperação internacionais. Essas dimensões são a nacionalidade das empresas e o tipo de cooperação desenvolvida. No primeiro caso, os acordos podem ser uninacionais (feitos para um único país), binacionais (dois países) ou multinacionais (vários países). No segundo caso, os acordos podem constituir-se como transacções em mercado aberto, acordos de cooperação interempresarial e acordos de cooperação intraempresarial.

Yoshino e Rangan (1995) desagregam as ligações interempresariais em função do tipo de contratos (tradicionais e não tradicionais) e do grau de envolvimento de capital (fusões e aquisições, e criação ou não criação de uma nova entidade). Para estes autores, as alianças estratégicas são ligações interempresariais que envolvem contratos não tradicionais (incluem neste caso vários acordos baseados em actividades como, por exemplo, produção ou investigação e desenvolvimento conjunto) ou arranjos de capital, excluindo as fusões e aquisições, e as joint ventures que são subsidiárias de multinacionais. Desta forma excluem do âmbito das alianças estratégicas acordos como o licenciamento e franquia que são considerados contratos tradicionais.

A literatura apresenta pois diferentes tipologias de alianças estratégicas. Verifica-se, no entanto, que nem sempre é suficientemente específica sobre o assunto e, por isso, como constata Root (1988), as generalizações, por vezes abstractas, são bastante habituais. Ainda que existam bastantes tipologias de alianças estratégicas, elas assentam sobretudo em critérios jurídicos e económicos. Aquelas que utilizam critérios jurídicos recorrem geralmente às seguintes dimensões de classificação: grau de formalização dos acordos, tipos de acordos relativamente à sua forma jurídica (tipo de contratos), e constituição ou não de uma entidade juridicamente autónoma. Por seu lado, as tipologias que envolvem critérios essencialmente económicos referem-se, por norma, às actividades objecto de cooperação, envolvimento de capital, objectivos da aliança, tipo de administração dos activos, e contexto da aliança (nacional, internacional ou outro). Verifica-se ainda que, freqüentemente, muitas classificações não são claras nos seus pressupostos de análise ou misturam critérios de forma pouco compreensível, contribuindo para o diagnóstico a que nos referimos anteriormente. A este diagnóstico deve ainda acrescentar-se que a relativa escassez de estudos empíricos também contribui para a situação apontada. Continuam assim a escassear tipologias con- 
sistentes, completas e concretas sobre as opções estratégicas, ao dispor das empresas que decidem enveredar pela constituição de alianças estratégicas.

Naturalmente, as tipologias são tanto mais importantes porque, por um lado, tornam o conceito de aliança estratégica menos difuso do que na realidade é, ilustrando as opções que se escondem sobre o seu vasto manto e, por outro lado, favorecem uma tomada de consciência prática sobre o tema. A fim de contribuir para o esclarecimento do tema, propõe-se de seguida uma tipologia sobre alianças estratégicas que se julga poder em colmatar algumas das limitações diagnosticadas na literatura.

\section{Proposta de Tíologia}

Decidiu-se criar uma tipologia que, sem descurar os aspectos teóricos, privilegiasse características práticas e tangíveis para as empresas. Antes dessa tipologia ser apresentada devem, no entanto, enquadrar-se as bases teóricas da proposta.

Para melhor compreender os tipos de alianças estratégicas recorreu-se a três elementos no estudo das relações empresariais à luz do paradigma das redes industriais (Håkansson, 1982; Ford, 1997). Esses elementos que têm merecido uma grande atenção por parte de vários autores (Johanson e Mattsson, 1988; Axelsson e Easton, 1992; Håkansson e Snehota, 1995), são os actores, actividades e recursos que compõem as relações entre organizações. Actores são indivíduos, grupos de indivíduos, partes de empresas, empresas ou grupos de empresas que controlam recursos e desenvolvem actividades. As actividades desenvolvem-se quando os actores criam, trocam, desenvolvem ou combinam recursos recorrendo a outros recursos. Os recursos são os meios utilizados pelos actores no desenvolvimento das suas actividades (Håkansson e Johanson, 1992).

Ainda que para ter uma visão global do fenómeno, actores, actividades e recursos envolvidos em alianças estratégicas devam ser considerados em conjunto, no âmbito deste artigo os actores e actividades merecem maior atenção. Além disso, o conceito de actores respeitará tão somente às empresas, seus principais clientes, fornecedores e empresas situadas na mesma fase do seu sistema de negócios $^{(1)}$, a que se chamarão unidades horizontais. Na perspectiva aqui adoptada, as actividades desenvolvidas pelos actores são um dos melhores critérios para classificar alianças estratégicas. No entendimento de Håkansson (1989) existem dois tipos fundamentais de actividades: actividades de produção e actividades de troca. As primeiras, também chamadas de actividades de transformação, são todas aquelas actividades que ocorrem no seio da empresa, enquanto as 
trocas, também chamadas de actividades de transferência, se verificam entre as empresas. Enquanto as actividades de produção são directamente controladas pela empresa, as actividades de troca ligam as actividades de produção de diferentes empresas e, como tal, são sujeitas ao controlo de pelo menos duas empresas. Desta forma, através das trocas, uma empresa transfere o controlo de recursos para outra empresa. Os ciclos de actividades entre empresas tendem a adquirir certa regularidade e periodicidade. Com a prática, no desenvolvimento dessas actividades, as empresas criam certas rotinas e regras informais que se vão institucionalizando e são a base do seu relacionamento. Reúnem-se assim condições de estabilidade organizacional e as relações e alianças tendem a adquirir uma dimensão estratégica.

Apesar da riqueza conceptual deste modelo, a simples distinção entre actividades de transformação e actividades de transferência não é, em nosso entender, suficiente para definir uma tipologia de alianças estratégicas. Por isso, julgou-se que o anterior modelo deve ser complementado através do conceito de cadeia de valor (Porter, 1985). Fazendo uso deste conceito, as actividades duma empresa podem ser desagregadas da seguinte forma: compras, produção, marketing e vendas, distribuição de produtos acabados, serviços pós-vendas, gestão de recursos humanos, e investigação e desenvolvimento tecnológico.

As compras incluem todas as actividades orientadas para a aquisição dos recursos necessários ao desenvolvimento das restantes actividades da empresa. A produção inclui todas as operações necessárias à transformação de inputs em produtos finais ou serviços. De acordo com Porter (1985), o marketing e vendas é uma actividade que induz e facilita a compra do produto por parte dos clientes. A distribuição dos produtos acabados inclui as iniciativas desenvolvidas a jusante do processo produtivo, através das quais a empresa disponibiliza a sua oferta no mercado. Os serviços pós-vendas são o complemento dos produtos acabados e em conjunto com estes fazem parte da oferta da empresa. As actividades de gestão de recursos humanos respeitam ao recrutamento, selecção e colocação, avaliação e compensação, e desenvolvimento pessoal dos indivíduos e grupos que integram a empresa. A investigação e desenvolvimento tecnológico inclui todas as actividades associadas à aquisição, criação e desenvolvimento de know-how na empresa.

Partindo destas actividades é possível identificar três domínios de cooperação: comercial, técnico ou de produção, e financeiro. A cada um destes domínios irão corresponder diferentes tipos de alianças estratégicas. No domínio comercial incluem-se as alianças estratégicas que são desenvolvidas predominantemente para uma ou várias das seguintes actividades: compras, marketing e vendas, distribuição de produtos acabados e serviços pós-vendas. No domínio técnico ou de produção as alianças estratégicas orientam-se fundamentalmente para activi- 
dades de produção, gestão de recursos humanos, e investigação e desenvolvimento tecnológico. Finalmente, no domínio financeiro categorizam-se as alianças em função do capital envolvido e grau de integração dos parceiros.

Naturalmente, reconhece-se, o critério prevalecente nesta tipologia é, em primeiro lugar, o das actividades, se bem que no domínio financeiro o grau de envolvimento de capital seja realçado. Para cada domínio de cooperação os Quadros 1,2 e 3 descrevem as principais características de cada um dos 16 tipos de alianças estratégicas que propomos. Seis tipos são do domínio comercial, seis do domínio técnico/produção e quatro do domínio financeiro.

\section{Quadro 1: Tipos de Alianças Estratégicas do Domínio Comercial}

\section{DESCRITIVO}

\section{Grupo de exportadores}

Conjunto de empresas do mesmo sector que cooperam entre si para desenvolvimento dos mercados externos. A cooperação dá-se em diferentes actividades: realização de estudos nos mercados externos, participação conjunta em feiras, publicidade, entre outras. Além das economias de escala desenvolvidas, uma das suas principais vantagens é a possibilidade do grupo poder oferecer uma gama de produtos mais larga.

\section{Acordo de distribuição}

Estabelece-se geralmente entre uma empresa produtora de bens finais e outra empresa que possui domínio ou presença nas redes de distribuição do produto ao consumidor final. Neste caso, o distribuidor acede ao produto do produtor e este acede a um ou vários canais de distribuição.

Acordo de representação

Verifica-se quando uma empresa se torna a representante dos produtos e marcas da outra empresa para determinado mercado. $\mathrm{O}$ acordo de representação distingue-se da franquia porque envolve um menor nível de integração entre os aliados. Ou seja, ao contrário da franquia, o acordo de representação nem sempre obriga à exclusividade da marca e, por outro lado, pode incluir ou não a distribuição do produto.

\section{Central de compras}

A aliança estratégica estabelece-se por forma a facilitar o acesso das empresas participantes aos seus inputs fundamentais. Por norma, as empresas são do mesmo sector e possuem as mesmas necessidades de matériasprimas ou outras. Através da cooperação na compra, elas podem desenvolver economias de escala e adquirir maior poder negocial junto dos fornecedores com repercussões não só em termos de preços mas também qualidade, condições de pagamento e condições de entrega.

\section{Franquia}

Ocorre quando uma empresa (franqueador) concede a outra (franquiado) o direito de explorar uma marca, produto ou técnica de sua propriedade num determinado mercado mediante determinadas condições contratuais. Estas condições envolvem contrapartidas financeiras e o cumprimento de procedimentos de gestão e políticas de marketing.

\section{Assistência comercial}

Ocorre quando uma empresa estabelece um acordo no sentido de poder externalizar a definição e, sobretudo, a implementação das suas políticas de marketing. Deste modo, a empresa concentra as suas competências noutras actividades, como, por exemplo, a inovação tecnológica dos processos de produção e desenvolvimento de novos produtos, deixando ao parceiro a tomada de algumas decisões comerciais. 
Relativamente a cada um dos tipos de alianças estratégicas deve notar-se que, apesar de individualmente eles realçarem uma ou outra actividade, as alianças só assumem uma dimensão estratégica quando afectam as restantes actividades da empresa. Esta foi aliás uma das características apresentadas na secção 2 como susceptível de distinguir uma aliança estratégica de uma aliança não estratégica ou operacional.

\section{Quadro 2: Tipos de Alianças Estratégicas do Domínio Técnico/Produção}

\section{DESCRITIVO}

\section{Consórcio}

Esta modalidade estabelece-se entre duas ou mais empresas que possuem capacidades e competências susceptíveis de poderem ser complementadas no desenvolvimento de um projecto técnico de grande envergadura e duração no tempo (por exemplo, construção de uma auto-estrada ou ponte). O consórcio pode ou não manter-se para além da realização de um projecto. Muitas vezes, o sucesso de um projecto motiva os parceiros para novos projectos e aprofundamento da relação.

\section{Formação e/ou assistência técnica}

Ocorrem com maior freqüência em sectores em que a base tecnológica é importante. Neste caso, estabelece-se um acordo entre duas ou mais empresas através do qual poderão ser ultrapassadas determinadas lacunas tecnológicas. Essas lacunas podem resultar da formação da mão-de-obra que não apresenta as qualificações e competências desejáveis ou de dificuldades de desempenho no equipamento de produção ou nos produtos.

\section{Subcontratação}

É um tipo de aliança estratégica através do qual uma empresa (contratante) subcontrata a outra (subcontratada) uma parte do seu processo de produção. Deste modo, as operações desenvolvidas por cada um dos parceiros são diferentes.

\section{Acordo de produção conjunta}

Verifica-se quando duas ou mais empresas produzem conjuntamente os mesmos produtos para satisfazer necessidades de mercado às quais não conseguiriam responder individualmente por falta de capacidade. Este tipo de aliança estratégica distingue-se da subcontratação pelo facto das empresas desenvolverem as mesmas actividades e, por isso, estarem presente na mesma fase do sistema de negócios. Ou seja, as operações desenvolvidas pelos parceiros são iguais.

\section{Acordo de investigação e desenvolvimento}

Verifica-se particularmente em sectores onde a actividade de investigação e desenvolvimento de novos produtos e processos assume um peso muito importante. Essa importância é visível na elevada percentagem de custos totais que são afectos à actividade de investigação e desenvolvimento. Esses custos são sobretudo custos fixos e, por isso, as empresas desenvolvem este tipo de alianças para poderem repartir os custos fixos. Por outro lado, podem desenvolver competências técnicas mais facilmente e responder ao mercado mais adequada ou rapidamente com novos produtos.

\section{Licenciamento de patentes}

Aliança estratégica através da qual uma empresa (concessionária) concede a outra (licenciada) os direitos de exploração de uma patente, produto ou processo de fabrico mediante uma compensação geralmente de carácter financeiro. 
Assim, por exemplo, apesar da actividade prevalecente num acordo de distribuição ser naturalmente a distribuição dos produtos acabados, este tipo de acordo só assume uma dimensão estratégica quando afecta as restantes actividades da empresa, ainda que o seu impacto não seja necessariamente igual em todas essas actividades. O mesmo pode ser dito, por exemplo, a propósito dum acordo de formação e/ou assistência técnica. Ou seja, nem todos os acordos com entidades formadoras ou prestadoras de assistência técnica são alianças estratégicas; só o são aqueles acordos que reúnem uma dimensão estratégica. Significa isto que uma aliança só é estratégica quando possui impacto nos três domínios, ainda que, naturalmente, tenha sido classificada num só domínio. Ou seja, uma aliança estratégica é por norma desenvolvida para uma ou várias actividades mas, directa ou indirectamente, acaba por envolver e ter implicações para as restantes actividades.

No caso das alianças estratégicas do domínio financeiro importa notar que a inclusão das fusões e aquisições é uma opção questionável pois, nestes casos, a autonomia de um dos parceiros desaparece e, em certa medida, deixa de haver uma aliança. Julgou-se, no entanto, que uma compreensão mais profunda das opções ao dispor das empresas requer a inclusão desses dois tipos.

\section{Quadro 3: Tipos de Alianças Estratégicas do Domínio Financeiro}

\section{DESCRITIVO}

Aquisição de empresa

Ocorre quando uma empresa adquire uma posição maioritária no capital de outra empresa.

Participação minoritária em empresa

Verifica-se quando uma empresa adquire uma posição inferior a $50 \%$ do capital de outra empresa.

\section{Joint venture}

Verifica-se quando duas ou mais empresas constituem uma nova entidade. As joint ventures são alianças estratégicas do domínio financeiro porque, tratando-se da constituição de uma nova entidade, envolvem, entre outros recursos, a afectação de capital para a sua estrutura accionista. Contudo, o desenvolvimento deste tipo de aliança é bastante comum para prosseguir objectivos comerciais ou de produção/técnicos.

Fusão

Representa o grau máximo de integração de duas ou mais empresas que decidem fundir as suas estruturas de capitais numa única entidade. 


\section{Método}

No estudo das alianças estratégicas têm sido aplicadas diferentes metodologias. Por exemplo, Hergert e Morris (1988) basearam-se nos acordos noticiados pelo The Economist e Financial Times entre 1975 e 1986 para estudar as tendências no estabelecimento de parcerias internacionais. Perseguindo objectivos idênticos, Ghemawat e Porter (1986) analisaram as alianças internacionais identificadas no The Wall Street Journal no período compreendido entre 1970 e 1982. Seguindo também uma perspectiva longitudinal, Vanhaverbeke e Duysters (1997) recorreram a uma base de dados desenvolvida na Universidade de Maastricht, Holanda, para estudar alianças estratégicas e aquisições em indústrias tecnologicamente intensivas, enquanto Gulati (1999) recorreu a diferentes fontes de dados sobre a actividade de alianças entre 1980 e 1989 de uma amostra de 166 grandes empresas de três sectores para identificar factores determinantes na formação de alianças.

Um problema comum a estes e muitos outros estudos sobre alianças estratégicas é o da delimitação do universo e escolha da amostra. De facto, à priori, nem sempre é viável a identificação das empresas envolvidas em alianças estratégicas, dificuldade que muitos investigadores acabam por ultrapassar recorrendo, como vimos, a bases de dados secundários ou a bases de dados comerciais. Também nós, na pretensão de analisar o perfil de cooperação e os tipos de alianças estratégicas desenvolvidas por empresas portuguesas, sentimos esta dificuldade.

Por isso, na pesquisa empírica, começou-se por analisar os mecanismos de promoção da cooperação ao dispor das empresas portuguesas. Dada a sua orientação e especificidade para promover a cooperação empresarial, reduziu-se a análise a vários programas e instrumentos da Comissão Europeia $(\mathrm{CE})^{(2)}$. O Plano Específico de Desenvolvimento da Indústria Portuguesa (PEDIP), o programa mais significativo no apoio ao investimento das empresas portuguesas na década de 90, também foi considerado; contudo rapidamente se concluiu que a promoção da cooperação empresarial nunca por ele foi abrangida de forma consequente. A realização do estudo exploratório envolveu uma consulta exaustiva e detalhada de documentação da CE e a realização de oito entrevistas junto de consultores (públicos e privados) e empresas com experiência nos programas e instrumentos da CE (alguns dos resultados mais significativos destas entrevistas são apresentados em Eiriz [1999]). Como resultado do estudo exploratório concluiu-se que, de entre os programas e instrumentos especificamente orientados para a promoção da cooperação que envolve empresas portuguesas, o programa Europartenariat se revelou o mais importante mecanismo de promoção da cooperação empresarial. 
O Europartenariat - Parceria entre Empresas é um programa da CE que possui como objectivo estimular o contacto e cooperação entre empresas de regiões menos desenvolvidas ou em declínio industrial e empresas de outras regiões. $\mathrm{O}$ programa está particularmente vocacionado para a cooperação entre pequenas e médias empresas (PMEs) dos Estados membros da UE ou destas com empresas de países do resto da Europa e Mediterrâneo, e assenta na realização de encontros periódicos entre empresas duma região hospedeira e empresas de outras regiões da Europa.

Em termos operacionais o Europartenariat consiste num encontro de dois dias numa dada região ou país europeu previamente seleccionado pela CE. Nesse encontro, as empresas locais (empresas hospedeiras) estabelecem contactos pessoais com as empresas visitantes de outras regiões e países. Os encontros são previamente marcados de acordo com os objectivos específicos de cada empresa. Assim, cada empresa hospedeira define previamente o perfil de cooperação desejado (por exemplo, encontrar um parceiro para aceder a um novo mercado, criar uma equipa conjunta de desenvolvimento de um novo produto, estabelecer uma parceria para compras etc.). Este perfil de cooperação e outros dados identificativos da empresa (nome da pessoa a contactar e a sua posição na empresa, breve descrição da empresa, código NACE - Nomenclature of Economic Activities in the European Community, volume de vendas, exportações, importações, número de empregados e ano da fundação da empresa) são publicados num catálogo nas várias línguas oficiais da UE que é distribuído e promovido pela $\mathrm{CE}$ com alguns meses de antecedência sobre a data do encontro. A partir desta divulgação os encontros são marcados com antecedência. No espaço dos dois dias estabelecem-se então vários contactos pessoais, a fim de se estabelecerem acordos de cooperação. Dificilmente são realizados acordos no espaço de dois dias, mas a partir desses primeiros contactos compete às empresas dar ou não seguimento aos seus projectos conjuntos.

Procedeu-se depois à aplicação de um questionário postal junto de empresas portuguesas participantes no Europartenariat, Portugal, 1995, último encontro realizado envolvendo empresas portuguesas como hospedeiras. Dada a natureza do Europartenariat, ao seleccionar estas empresas tinha-se a garantia de que num passado recente elas tinham demonstrado interesse em desenvolver projectos de cooperação, ainda que, obviamente, não havia a noção do seu estado em termos de participarem ou não em alianças estratégias. Julgou-se, no entanto, que o tempo decorrido entre o encontro e a aplicação do questionário (12 meses) foi um período adequado para que as empresas tomassem decisões sobre os projectos de cooperação em consideração. Assim, à data do questionário, as empresas provavelmente estariam já envolvidas em projectos ou, pelo menos, teriam vivido um período de experiência e aprendizagem sobre o tema que consideramos im- 
portante para a pesquisa. Para o estudo quantitativo, a população era assim constituída pelas 406 empresas portuguesas que participaram como hospedeiras no encontro referido. Relativamente a estas empresas tivemos acesso ao catálogo da iniciativa e, como tal, os dados secundários mencionados anteriormente estavam disponíveis.

$\mathrm{Na}$ escolha da amostra seguiram-se alguns procedimentos que importa analisar. Começou-se por eliminar empresas de serviços e comércio (59 empresas). Esta opção resultou, de um lado, por motivos que se baseiam na delimitação do objecto de estudo a empresas industriais. De outro lado, como resultado do estudo exploratório, concluiu-se que a intenção predominante da participação destas empresas no encontro era prestar os seus serviços de consultoria de apoio à cooperação das restantes empresas numa perspectiva de venda imediata e não desenvolver alianças estratégicas ou relações de negócio baseadas na cooperação empresarial de longo prazo. Para as restantes 347 empresas efectuou-se a sua repartição por sectores (códigos NACE com dois dígitos), tendo obtido um total de 20 sectores. De entre estes, eliminaram-se todos os que não tinham mais de 10 empresas constituintes. Ao ser definido como condição de escolha de um sector a existência de mais de 10 empresas conseguiu-se reduzir substancialmente o número de sectores. Deste modo, a amostra era de 293 empresas, representando 11 sectores da indústria transformadora ${ }^{(3)}$. Procedeu-se ainda à realização de testes na versão preliminar do questionário. Estes testes decorreram junto de 7 empresas que, tanto quanto possível, se procurou que fossem representativas da amostra em termos de dimensão, actividade exportadora e diversidade sectorial. Do total da amostra foram excluídas essas empresas, pelo que o questionário final foi aplicado sobre 286 empresas em novembro de 1996.

O envio postal do questionário foi precedido de uma carta personalizada (recorde-se que possuíamos a identificação de um responsável da empresa, geralmente um gestor de topo) a solicitar a participação da empresa no estudo. Dos questionários recebidos até janeiro de 1997 foram excluídos 4 por preencher, tendo-se obtido um total de 133 questionários válidos para tratamento de dados, $\mathrm{o}$ que corresponde uma taxa de resposta de $46,5 \%$. A taxa de resposta obtida é claramente superior ao que é costume em estudos similares. Tal só foi possível porque as empresas foram contactadas de forma personalizada, em primeiro lugar através de uma carta prévia a destacar a importância do estudo e solicitar a sua participação e, depois, devido ao facto de se ter incluído envelope de resposta pré-pago, e efectuado dois reforços de pedido de resposta (um por carta e outro por fax). A caracterização dos principais indicadores das empresas respondentes foi obtida através dos dados secundários referidos anteriormente ${ }^{(4)}$.

O volume médio de vendas das empresas respondentes é de 7.654 .442 reais $^{(5)}$ do qual em média exportam 31,9\%. Da análise do volume médio de vendas por 
sector verifica-se que as empresas alimentares e de bebidas apresentam a maior dimensão, enquanto as do mobiliário, outros produtos minerais não metálicos, e artigos de borracha e matérias plásticas são, em média, as empresas mais pequenas. Noutro indicador de dimensão as empresas possuem em média 95 trabalhadores. Verifica-se, no entanto, que os fabricantes de têxteis possuem um número médio de empregados (147) bastante superior às empresas de produtos químicos que possuem o menor valor médio (56). Os resultados destes dois indicadores reflectem as diferentes características dos sectores da amostra em termos da intensidade de mão-de-obra empregada, capital e tecnologia. Realçando outras características gerais, constata-se que a antiguidade média das empresas é de 25 anos e todos os sectores apresentam uma idade média superior a 17 anos. No total das 133 empresas, a empresa mais nova tem 2 anos de idade e a mais antiga 116 anos.

\section{Envolvimento em Alianças Estratégicas}

Sobre os tipos de alianças estratégicas em que as empresas estão actualmente envolvidas os resultados globais mostram que uma clara maioria das 133 empresas $(60,1 \%, 80$ empresas) possui pelo menos uma aliança estratégica. Perante a questão de saber se as empresas desejam no futuro envolver-se em alianças estratégicas a percentagem de respostas positivas sobe para 90,9\% (121 empresas). Ou seja, há um número importante de empresas que à data do questionário não estava envolvida em alianças estratégicas mas, talvez reconhecendo a validade desta opção, pretendia vir a fazê-lo no futuro, mostrando assim uma tendência positiva no desenvolvimento de alianças estratégicas.

Ainda relativamente ao envolvimento actual das empresas é possível analisar em quantos tipos de alianças estratégicas elas se envolvem. Os resultados evidenciam claramente que uma parte significativa das empresas respondentes $(54,8 \%)$ possuem um ou dois tipos de alianças estratégicas e $22,6 \%$ envolvemse em três ou quatro tipos.

No estudo da intensidade com que as empresas que responderam à questão (93 empresas) se envolvem em alianças estratégicas verificaram-se correlações significativamente relevantes, ainda que de baixo valor, com o volume de importações (nível de significância $\alpha=0,01, \mathrm{r}=0,349$ ), volume de vendas (nível de significância $\alpha=0,01, r=0,298$ ) e volume de exportações (nível de significância $\alpha=0,05$, $\mathrm{r}=0,222$ ), não se tendo confirmado a hipótese de associação linear com a taxa de exportações (quociente entre o volume de exportações e o volume de vendas) e com a taxa de importações (quociente entre o volume de importações e o 
volume de compras). Verificou-se assim que a dimensão é uma variável que aparece associada à actividade com que as empresas se envolvem em alianças estratégicas. $\mathrm{O}$ facto das maiores empresas terem uma maior propensão para desenvolver alianças estratégicas poderá resultar do facto de serem também elas que possuem maiores recursos (quadros técnicos, competências etc.) que lhes permite estar mais conscientes da importância das alianças estratégicas e actuar em conformidade.

A decomposição dos resultados por tipo de aliança estratégica mostra que a subcontratação, praticada por $43,8 \%$ das empresas que desenvolvem alianças, acordos de representação $(40,0 \%)$ e acordos de distribuição $(35,0 \%)$, são os tipos predominantes. Estes três tipos, em conjunto, representam 51,4\% dos tipos de alianças estratégicas em que as empresas estão envolvidas. Estes resultados confirmam, por um lado, a importância atribuída à subcontratação na estratégia das empresas industriais portuguesas e, por outro lado, reflectem o valor atribuído às alianças estratégicas do domínio comercial. Esta leitura parece traduzir uma grande consistência. Efectivamente, é de crer que o comportamento tradicional das empresas industriais portuguesas, atribuindo uma grande importância à subcontratação, se mantenha, ainda que tenham vindo a ser desenvolvidos esforços no sentido de criar novas relações industriais junto dos mercados compradores e consumidores, nomeadamente através de acordos de representação e acordos de distribuição.

A análise dos resultados globais por domínio de cooperação (vide Tabela 1) mostra que o domínio técnico/produção ( 85 alianças / 46\%) e o domínio comercial (82 / 44,3\%) possuem uma actividade bastante idêntica e substancialmente superior à registada no domínio financeiro $(18 / 9,7 \%)$. Estes valores vão de encontro à hipótese de que raramente as empresas desenvolvem alianças estratégicas por motivos exclusivamente financeiros.

Tabela 1: Domínios de Cooperação Empresarial por Sector (Actualmente)

\begin{tabular}{lccccccccccccc}
\hline NACE & 15 & 17 & 18 & 20 & 24 & 25 & 26 & 28 & 29 & 31 & 36 & TOTAL & N \\
DOMÍNIO & & & & & & & & & & & & & \\
\hline Comercial & 19,5 & 6,1 & 18,3 & 3,7 & 3,7 & 9,8 & 1,2 & 12,2 & 6,1 & 6,1 & 13,4 & $\mathbf{1 0 0 \%}$ & $\mathbf{8 2}$ \\
Técnico/produção & 8,2 & 8,2 & 15,3 & 3,5 & 5,9 & 8,2 & 2,4 & 11,8 & 14,1 & 7,1 & 15,3 & $\mathbf{1 0 0} \%$ & $\mathbf{8 5}$ \\
Financeiro & 11,1 & 11,1 & 16,7 & 5,6 & 16,7 & 0 & 5,6 & 11,1 & 22,2 & 0 & 0 & $\mathbf{1 0 0 \%}$ & $\mathbf{1 8}$ \\
\hline Total & 13,5 & 7,6 & 16,8 & 3,8 & 5,9 & 8,1 & 2,2 & 11,4 & 11,3 & 5,9 & 13,0 & $\mathbf{1 0 0} \%$ & $\mathbf{1 8 5}$ \\
\hline
\end{tabular}

Resultados mais relevantes. 
A repartição das 185 alianças estratégicas em curso por sector evidencia que os sectores do vestuário (NACE 18) com 16,8\%, alimentar e bebidas (NACE 15) com 13,5\%, e mobiliário (NACE 36) com 13,0\% respondem pelo maior número de alianças estratégicas. A ponderação destes resultados em função do número de respostas permite concluir quais os sectores que apresentam uma actividade mais intensa no desenvolvimento de alianças estratégicas. Verifica-se assim que o sector de fabricação de máquinas e de equipamentos (NACE 29) é aquele que apresenta uma maior actividade de alianças estratégicas por empresa, representando, em média, 3,5 alianças por empresa, seguido da indústria têxtil (NACE 17), e alimentar e bebidas (NACE 15). No lado oposto, com menor actividade encontra-se o sector de outros produtos minerais não metálicos (NACE 26), que apresenta uma média de uma aliança por empresa.

A leitura dos resultados por domínio de cooperação permite ainda concluir que o sector alimentar e bebidas (NACE 15), logo seguido do vestuário (NACE 18), são os que possuem maior número de alianças estratégicas do domínio comercial e são também aqueles que, conjuntamente com o têxtil (NACE 17), possuem maior índice de actividade. No domínio técnico/produção, destacam-se o vestuário (NACE 18), mobiliário (NACE 36) e máquinas e equipamentos (NACE 29); contudo a ponderação destes resultados coloca uma vez mais o sector de fabricação de máquinas e equipamento (NACE 29) num lugar destacado. Finalmente, no domínio financeiro, embora os índices de actividade sejam bastante reduzidos, o sector de máquinas e equipamentos (NACE 29) é novamente o que possui maior número de alianças e maior índice de actividade.

Relativamente à distribuição dos tipos de alianças estratégicas mais comuns (subcontratação, acordos de distribuição e acordos de representação) por sector verifica-se que: (1) a subcontratação é mais intensa no vestuário (NACE 18), produtos metálicos, excepto máquinas e equipamentos (NACE 28) e mobiliário (NACE 36) que, em conjunto, representam $60 \%$ dos acordos de subcontratação; (2) os acordos de representação verificam-se sobretudo no sector alimentar e bebidas (NACE 15) e vestuário (NACE 18) que, em conjunto, representam 37,1\% do total de acordos de representação; (3) os acordos de distribuição são também bastante comuns no sector alimentar e bebidas (NACE 15), seguido do sector dos artigos de borracha e de matérias plásticas (NACE 25) e mobiliário (NACE 36) que, em conjunto, respondem por $53,6 \%$ do total destes acordos.

As empresas foram também inquiridas sobre a sua pretensão em desenvolver alianças estratégicas no futuro. Os resultados sobre a actividade futura permitem concluir que os acordos de distribuição são o tipo de aliança desejado por 49,6\% das 121 empresas que pretendem desenvolver alianças estratégicas. Este resultado sugere uma tomada de consciência das empresas industriais sobre a impor- 
tância das actividades a jusante da sua cadeia de valor, ou seja, da relevância de desenvolver estratégias que as aproximem do consumidor final.

No domínio comercial importa ainda realçar que os grupos de exportadores são um tipo de aliança bastante desejado para o futuro, situação visível na grande variação entre empresas que fazem actualmente parte de um grupo de exportadores (8 empresas) e que desejam vir a fazer parte no futuro (48). No mesmo nível de actividade futura dos grupos de exportadores encontram-se os acordos de representação (também com 48 empresas), se bem que a variação registrada entre a actividade actual e futura seja claramente inferior à verificada para os grupos de exportadores.

A tomada de consciência sobre a importância das actividades a jusante da cadeia de valor referida anteriormente poderá ser sedimentada com o facto de 53 empresas $(43,8 \%)$ desejarem vir a constituir joint ventures. Apesar deste tipo de aliança envolver capital e ter sido classificada no domínio financeiro, admite-se que é uma estratégia bastante usada para desenvolver novos mercados, particularmente em processos de internacionalização e, como tal, visa a objectivos de natureza comercial. Naturalmente, esta observação carece de ser comprovada empiricamente, tanto mais que é bastante habitual uma joint venture perseguir objectivos de natureza não comercial como, por exemplo, a deslocalização de unidades produtivas de um país para outro, onde os custos de produção são inferiores. Deve ainda ser realçado que as joint ventures, possuindo pouca importância actualmente ( 5 empresas / 6,3\%), são um dos tipos de aliança mais desejado para o futuro $(53 / 43,8 \%)$.

Por seu lado, os resultados obtidos no domínio técnico/produção (42,1\% desejam estabelecer acordos de produção conjunta e 37,2\% acordos de investigação e desenvolvimento) parecem indicar que estas empresas desejam estabelecer relações industriais de partilha da produção e desenvolvimento de novas competências através da investigação e desenvolvimento. Esta conclusão é, em parte, esteada pela perda de importância da subcontratação, que é um tipo de aliança estratégica em que, por norma, as empresas portuguesas actuam como subcontratadas de parceiros externos com o domínio de marcas e circuitos de distribuição e, como tal, existe um desequilíbrio de poder que lhes é desfavorável. Esta situação poderá indicar o desenvolvimento de novas relações que facilitem o acesso a recursos, quer em termos de conhecimento dos circuitos de distribuição e mercados, quer na aposta em factores intangíveis de competitividade (design, concepção de novos produtos, marcas, qualidade, serviço) sem os quais as tradicionais vantagens competitivas por via dos custos de produção não são plenamente aproveitadas. 
A ponderação dos resultados sobre a actividade futura em função do número de empresas respondentes coloca o sector têxtil (NACE 17) num claro primeiro lugar, seguindo-se o sector de máquinas e equipamentos (NACE 29) e de fabricação de produtos metálicos excepto máquinas e equipamentos (NACE 28). No lado oposto encontram-se o sector de máquinas e aparelhos eléctricos (NACE 31 ). Relativamente a estes resultados repare-se que, quando comparados os resultados da actividade futura com a actividade actual, os sectores com maior índice de actividade são praticamente os mesmos. Os sectores têxtil (NACE 17) e máquinas e equipamentos (NACE 29) sobressaem, assim, como aqueles que apresentam maior dinâmica no desenvolvimento de alianças estratégicas.

\section{Principais Parceiros}

Neste estudo questionámos também as empresas sobre as alianças estratégicas existentes com os seus principais fornecedores, clientes e unidades horizontais. Esta escolha foi motivada pela convicção de que as alianças estratégicas são uma opção particularmente recorrente entre empresas com fortes relações de negócio. Para cada caso, questionou-se a empresa sobre as suas relações com três outras empresas. No caso dos fornecedores e clientes as três principais empresas são definidas, respectivamente, em função do seu peso nas compras e nas vendas da empresa inquirida. No caso das unidades horizontais, o critério indicado aos inquiridos para a escolha das três principais empresas foi o da sua importância para a empresa inquirida. Apesar da subjectividade deste critério, entendeu-se ser o mais adequado para testar as estratégias de cooperação com empresas situadas na mesma fase do sistema de negócios. Deste modo, concedeu-se uma margem de liberdade de escolha julgada aconselhável para facilitar o inquirido a seleccionar as empresas com que existam ligações mais fortes.

A análise da importância de cada um dos três maiores fornecedores revela que, em média, as empresas efectuam $32,9 \%$ das suas compras ao maior fornecedor, $16,4 \%$ ao segundo maior e $11,8 \%$ ao terceiro maior fornecedor. No caso do primeiro fornecedor, constata-se que $17,2 \%$ das empresas efectua pelo menos $50 \%$ das suas compras a esse fornecedor. Relativamente à importância de cada um dos três maiores clientes constata-se que, em média, o primeiro cliente das empresas é responsável por $21,4 \%$ das suas vendas; o segundo representa $13,1 \%$; o terceiro $9,5 \%$, enquanto só $4,6 \%$ das empresas efectua vendas de pelo menos $50 \%$ do total das vendas ao seu maior cliente. Estes resultados indicam uma maior concentração nas compras do que nas vendas, situação que tende a verificar-se tradicionalmente em mercados industriais. As percentagens indica- 
das são ainda bons indicadores do grau de dependência das empresas inquiridas relativamente aos seus clientes e fornecedores.

Os resultados globais sobre o envolvimento das empresas em alianças estratégicas com cada um dos três principais fornecedores, clientes e unidades horizontais evidenciam que as empresas possuem ligações mais fortes a jusante da sua cadeia de valor do que a montante ou lateralmente (vide Tabela 2).

\section{Tabela 2: Envolvimento em Alianças Estratégicas com os Principais Parceiros}

\begin{tabular}{|c|c|c|c|c|c|c|c|c|c|}
\hline & \multicolumn{3}{|c|}{ FORNECEDORES } & \multicolumn{3}{|c|}{ CLIENTES } & \multicolumn{3}{|c|}{ UNID. HORIZONTAIS } \\
\hline & $1 .^{\mathrm{o}}$ & $2 .^{\circ}$ & $3 .^{\circ}$ & $1 .^{\mathrm{o}}$ & $2 .^{\mathrm{o}}$ & $3 .^{\circ}$ & $1 .^{\mathrm{a}}$ & $2 .^{\mathrm{a}}$ & $3 .^{\mathrm{a}}$ \\
\hline $\operatorname{Sim}$ & 41,4 & 38,3 & 36,8 & 66,1 & 58,6 & 57,9 & 35,3 & 29,3 & 28,6 \\
\hline Não & 44,3 & 45,9 & 45,9 & 27,1 & 30,1 & 30,8 & 46,7 & 48,1 & 44,3 \\
\hline $\mathrm{N} / \mathrm{R}$ & 14,3 & 15,8 & 17,3 & 6,8 & 11,3 & 11,3 & 18,0 & 22,6 & 27,1 \\
\hline Total & 100 & 100 & 100 & 100 & 100 & 100 & 100 & 100 & 100 \\
\hline
\end{tabular}

Esta conclusão resulta da constatação de que na relação com cada um dos seus principais fornecedores, as empresas reconhecem maioritariamente que não possuem alianças estratégicas. Pelo contrário, na relação com cada um dos seus três principais clientes é reconhecido pela maioria das empresas que possuem alianças estratégicas. No concernente à relação com unidades horizontais a conclusão é idêntica à obtida para os fornecedores, ou seja, a maior percentagem de empresas reconhece não possuir alianças estratégicas com aquelas empresas. Este resultado reforça a anterior conclusão de que as empresas colocam maior esforço nas suas relações a jusante do que a montante ou horizontalmente. Significativo é também o facto de que $66,1 \%$ das 133 empresas inquiridas estão envolvidas numa aliança estratégica com o seu maior cliente, o que, uma vez mais, denota a importância do principais parceiros comerciais.

Relativamente às empresas que se envolvem em alianças estratégicas com os seus principais parceiros comerciais (fornecedores e clientes) e com unidades horizontais, efectuou-se uma análise dos domínios de cooperação e respectivos tipos de alianças estratégicas estabelecidas. O resumo dos resultados (vide Tabela 3) permite tirar conclusões muito claras. 


\section{Tabela 3: Domínios de Cooperação com os Principais Parceiros}

\begin{tabular}{lccccccccc}
\hline \multicolumn{1}{c}{ PARCEIRO } & \multicolumn{3}{c}{ FORNECEDORES } & \multicolumn{3}{c}{ CLIENTES } & \multicolumn{3}{c}{ UNID. HORIZONTAIS } \\
DOMÍNIO & $1 .^{\circ}$ & $2 .^{\circ}$ & $3 .^{\circ}$ & $1 .^{\circ}$ & $2 .^{\circ}$ & $3 .^{\circ}$ & $1 .{ }^{\mathrm{a}}$ & $2 .^{\mathrm{a}}$ & $3 .^{\mathrm{a}}$ \\
\hline $\begin{array}{l}\text { Domínio comercial } \\
\text { Domínio }\end{array}$ & 49,5 & 54,1 & 53,2 & 62,9 & 64,9 & 67,3 & 34,7 & 33,9 & 37,9 \\
técnico/produção & 44,1 & 41,9 & 43,0 & 33,6 & 33,3 & 30,9 & 60,0 & 58,9 & 55,2 \\
Domínio financeiro & 6,5 & 4,1 & 3,8 & 3,6 & 1,8 & 1,8 & 5,3 & 7,1 & 6,9 \\
\hline Total & $\mathbf{1 0 0}$ & $\mathbf{1 0 0}$ & $\mathbf{1 0 0}$ & $\mathbf{1 0 0}$ & $\mathbf{1 0 0}$ & $\mathbf{1 0 0}$ & $\mathbf{1 0 0}$ & $\mathbf{1 0 0}$ & $\mathbf{1 0 0}$ \\
\hline
\end{tabular}

Resultados mais relevantes.

Nas alianças estabelecidas com qualquer um dos três maiores fornecedores e clientes, sobressai claramente o domínio comercial. Como seria de esperar, o peso relativo das alianças do domínio comercial é bem superior junto dos três principais clientes do que dos três principais fornecedores. Também não surpreendem os resultados sobre as alianças existentes com unidades horizontais. Neste caso, para qualquer uma das três unidades horizontais identificadas como mais importantes prevalece o domínio técnico/produção da cooperação. Estes resultados vão ao encontro da ideia generalizada de que o maior esforço comercial das empresas é feito junto dos seus clientes e, só depois, dos fornecedores, enquanto a cooperação com unidades horizontais, na medida em que as empresas podem utilizar tecnologias e sistemas de produção idênticos ou complementares (recorde-se que se trata de unidades na mesma fase do sistema de negócios) baseia-se, sobretudo, no domínio técnico e de produção.

A decomposição dos resultados por tipos de alianças estratégicas permitiu também chegar a conclusões bastante consistentes. Assim, para qualquer um dos três principais fornecedores, o tipo de aliança mais comum é a assistência comercial. No caso das alianças com cada um dos três maiores clientes, são os acordos de distribuição que existem em maior número. Finalmente, na relação com unidades horizontais o tipo de aliança predominante é a subcontratação, situação que poderá pressupor a complementaridade entre empresas. Se o resultado obtido com clientes e unidades horizontais não surpreende e ser, em certa medida, esperado, o mesmo já não sucede com o resultado dos fornecedores, onde prevalece a assistência comercial. É de supor que, nestes casos, as empresas estudadas sejam assistidas comercialmente na componente técnica dos produtos que adquirem. Efectivamente, em mercados industriais, a especificidade das matérias adquiridas pode levar ao desenvolvimento de relações de permuta de informação técnica, interpretadas pelos inquiridos como assistência comercial recebida dos seus fornecedores. 
Da leitura do número médio de alianças estratégicas desenvolvidas por cada empresa com os seus principais parceiros conclui-se que o valor médio de alianças com o primeiro fornecedor, cliente ou unidade horizontal é superior à média obtida para o segundo e terceiro. Em termos globais, identificaram-se 246 alianças com os três maiores fornecedores, $361 \mathrm{com}$ os três maiores clientes e 189 com as três unidades horizontais mais importantes, num total de 796 alianças estratégicas. Os resultados mostram que o número de alianças estratégicas com os três clientes são maioritariamente entre três e quatro e só $28,8 \%$ dos respondentes não possuem nenhuma aliança com qualquer um dos seus três maiores clientes. Relativamente aos três maiores fornecedores, uma percentagem significativa das empresas $(47,4 \%)$ não possuem nenhuma aliança, mas $40,5 \%$ delas possuem pelo menos três alianças. Finalmente, só no caso das três unidades horizontais é que o número de empresas que não possui nenhuma aliança com aqueles parceiros é maioritário $(55,0 \%)$, havendo três ou mais alianças para $34 \%$ das empresas.

Da identificação da actividade total de alianças com os parceiros em estudo, constatou-se que 25 empresas $(19,2 \%)$ de entre as 130 respondentes não possuem nenhuma aliança estratégica. A repartição das empresas pelo número de alianças que possuem com os nove parceiros estudados mostra que $47,7 \%$ das empresas possuem pelo menos seis alianças estratégicas com os nove parceiros, enquanto $33,1 \%$ possuem entre uma e cinco alianças.

\section{Limitações, Sugestóes e Conclusões}

Naturalmente, muitas questões e problemas decorrentes da cooperação entre empresas e alianças estratégicas merecem continuar a ser estudados. Da análise cuidada dos anteriores resultados é possível detectar algumas limitações do estudo desenvolvido e, simultaneamente, sugerir pistas para trabalhos futuros de investigação. Sobre a análise sectorial das estratégias de cooperação, parece de todo aconselhável que se desenvolvam estudos futuros focalizados em sectores específicos, quer façam parte da indústria, quer dos serviços. Neste sentido, ainda que a taxa de resposta obtida no questionário tenha sido claramente superior ao que é costume neste tipo de estudos, o elevado número de sectores presentes na amostra (11) e o baixo número de empresas por sector (entre 5 e 18 empresas consoante o sector) podem colocar problemas de representatividade. Sobre a análise sectorial, interessaria compreender que características específicas de cada sector favorecem ou retraem o desenvolvimento de alianças estratégicas. Por exemplo, será maior a actividade de alianças estratégicas nos sectores tecnologi- 
camente intensivos? Terá grande influência o facto de um sector estar mais ou menos exposto à concorrência internacional? Resumindo, que características das actividades, actores e recursos dum sector podem (des)incentivar o desenvolvimento de alianças estratégicas? Neste sentido, seria de grande utilidade, ultrapassar o caráter algo descritivo do nosso estudo e, utilizando metodologias complementares à discutida neste artigo, explicar por que nalguns sectores prevalecem certos domínios de cooperação e tipos de alianças estratégicas e noutros sectores outros tipos muito distintos. Dito de outra forma, interessará compreender por que e como se estabelecem diferentes dinâmicas cooperativas entre sectores.

Se bem que a nossa opção tenha recaído na análise das relações com clientes, fornecedores e unidades horizontais, ainda que reduzidas aos principais parceiros, reconhece-se que será de extrema relevância que novos trabalhos se debrucem com maior profundidade no estudo das relações num único sentido (a montante, a jusante ou horizontalmente). Em particular interessará compreender o que distingue e assemelha a cooperação através de alianças estratégicas e outras formas de relacionamento em sistemas verticais (basicamente com fornecedores e clientes) das que se estabelecem em sistemas horizontais (com unidades horizontais). Mais importante ainda será estudar como as empresas alternam e/ou conciliam o seu comportamento competitivo (por exemplo, negociando preços com clientes e fornecedores ou relacionando-se com empresas rivais) com o comportamento cooperativo que necessariamente tem de estar presente nas alianças estratégicas.

Outro tipo de relações e alianças estratégicas que deve merecer a nossa atenção é aquele que se estabelece com organizações do sector público, corpos profissionais ou outro tipo de organizações (por exemplo, organizações não governamentais). A este propósito importa chamar a atenção para isto: as alianças estratégicas também podem ser estabelecidas entre empresas e organizações públicas, organizações não governamentais ou corpos profissionais. É de admitir que, nestes casos, a complexidade dos acordos pode ser maior do que nos casos em que ambas as organizações possuem um propósito idêntico e uma estrutura de propriedade semelhante. Por exemplo, até que ponto a diferente natureza de actividades entre uma organização que visa ao lucro, privada ou não, e uma organização não lucrativa, pública ou não, dificulta ou facilita o entendimento entre parceiros?

É ainda de todo o interesse que se estudem individualmente os diferentes tipos de alianças estratégicas, já que, por exemplo, os problemas colocados no nível da gestão de um acordo de subcontratação são claramente distintos das questões que se colocam, por exemplo, nas parcerias nos circuitos de distribuição. 
Com bastante interesse para futuras pesquisas é ainda a análise da forma como empresas portuguesas e brasileiras estão a utilizar joint ventures e outros tipos de alianças estratégicas nos seus processos de internacionalização. Em particular, de que forma as empresas portuguesas estão a abordar o mercado brasileiro através de alianças estratégicas com parceiros locais, e como empresas brasileiras podem utilizar Portugal como aliado para as suas operações na Europa? Serão os factores culturais e linguísticos importantes para fomentar alianças estratégicas no contexto internacional? Será a distância física uma barreira?

Sobre os resultados obtidos na pesquisa empírica importa reter que as empresas estudadas apresentam indicadores de cooperação bastante positivos. Verificou-se ainda que a intensidade de alianças estratégicas está associada à dimensão das empresas; a intensidade global de alianças estratégicas varia consoante o sector de actividade; a importância de cada tipo de aliança estratégica é também variável por sector de actividade; e a importância de cada tipo de aliança estratégica é variável, consoante o tipo de parceiro envolvido do outro lado da relação. No consentâneo à tipologia de alianças estratégicas proposta, admite-se que poderá constituir uma referência particularmente útil para organizações que equacionam opções estratégicas de cooperação com fornecedores, clientes e unidades horizontais.

\section{NOTAS}

\footnotetext{
${ }^{1}$ Um sistema de negócios é um conjunto de cadeias de valor de várias empresas que se relacionam enquanto fornecedoras, clientes e unidades horizontais (empresas colocadas na mesma fase do sistema de negócios).

${ }^{2}$ A Comissão Europeia é o órgão de governo da União Europeia (UE).

${ }^{3}$ Os sectores representados na amostra são os seguintes: alimentar e bebidas (NACE 15), têxteis (NACE 17), vestuário (NACE 18), madeira, cortiça e suas obras, excepto mobiliário (NACE 20), produtos químicos (NACE 24), artigos de borracha e de matérias plásticas (NACE 25), outros produtos minerais não metálicos (NACE 26), produtos metálicos, excepto máquinas e equipamento (NACE 28), máquinas e equipamentos (NACE 29), máquinas e aparelhos eléctricos (NACE 31), mobiliário (NACE 36).

${ }^{4}$ Destacamos o facto de o questionário incluir perguntas de controlo da validade dos dados secundários, tendo-se concluído através da realização de testes comparativos pela sua fiabilidade.

${ }^{5}$ A taxa de câmbio adoptada é de 1 real $=120$ escudos.
} 


\section{Referencias Bibliográficas}

AAKER, D. A.

Strategic market management.

New York : John Wiley \& Sons, 1995.

AXELSSON, B.;

EASTON, G. (Eds.).

Industrial networks : a new view of reality. London : Routledge, 1992.

DOUGLAS, S. P.;

CRAIG, C. S.

Global marketing strategy. New York : McGraw-Hill, 1995.

\section{EIRIZ, V.}

Cooperação empresarial : a perspectiva dos consultores. Cadernos de Economia, n. 49, p. 90 99, out./dez. 1999.

\section{FAULKNER, D.}

Strategic alliances : cooperation for competition. In: FAULKNER, D.; JOHNSON, G. (Eds.). The challenge of strategic management. London : Kogan Page, 1992.

FORD, D. (Ed.).

\section{Understanding business markets : interaction,}

relationships and networks. London : The Dryden Press, 1997.

GHEMAWAT, P.;

PORTER, M. E.

Patterns of international coalition activity. In: PORTER, M. E. (Ed.). Competition in global industries. Boston, MA : Harvard Business School Press, 1986. p. 345-365.

GULATI, R.

Network location and learning : the influence of network resources and firm capabilities on alliance formation. Strategic Management Journal, v. 20, n. 5, p. 397-420, May 1999.

HÅKANSSON, H. (Ed.).

International marketing and purchasing of industrial goods : an interaction approach. New York : John Wiley \& Sons, 1982.

Corporate technological behaviour : co-operation and networks. London : Routledge, 1989. 
HÅKANSSON, H.;

JOHANSON, J.

Formal and informal cooperation strategies in international industrial networks. In: CONTRACTOR, F. J.; LORANGE, P. (Eds.). Cooperative strategies in international business : joint ventures and technology partnerships between firms. New York : Lexington Books, 1988. p. 369-379.

A model of industrial networks. In: AXELSSON, B.; EASTON, G. (Eds.). Industrial networks : a new view of reality. London : Routledge, 1992. p. 28-34.

HÅKANSSON, H.;

SNEHOTA, I. (Eds.).

Developing relationships in business networks. London : Routledge, 1995.

HAX, A. C.;

MAJLUF, N. S.

The concept of strategy and the strategy formation process. Interfaces, v. 18, n. 3, p. 99-109, May/June 1988.

HERGERT, M.;

MORRIS, D.

Trends in international collaborative agreements. In: CONTRACTOR, F. J.;
LORANGE, P. (Eds.). Cooperative strategies in international business : joint ventures and technology partnerships between firms. New York : Lexington Books, 1988. p. 99-109.

JOHNSON, G.;

SCHOLES, K.

Exploring corporate strategy. 5. Ed. New York : Prentice Hall, 1999.

JOHANSON, J.;

MATTSSON, L.-G.

Internationalization in industrial systems : a network approach. In: BUCKLEY, P. J.; GHAURI, P. (Eds.). The internationalization of the firm : a reader. London : Academic Press, 1993. p. 303321.

LORANGE, P.;

ROOS, J.

Strategic alliances : formation, implementation and evolution. Oxford : Blackwell, 1993.

PORTER, M. E.

Competitive advantage : creating and sustaining superior performance. New York : Free Press, 1985. 
ROOT, F. R.

Some taxonomies of international cooperative arrangements. In: CONTRACTOR, F. J.; LORANGE, P. (Eds.). Cooperative strategies in international business : joint ventures and technology partnerships between firms. New York : Lexington Books, 1988. p. 69-80.

THORELLI, H. B.

Networks : between markets and hierarchies. Strategic Management Journal, v. 7, n. 1, p. 37-51, Jan./ Feb. 1986.

VANHAVERBEKE, W.;

DUYSTERS, G.

A longitudinal analysis of the choice between technology-based strategic alliances and acquisitions in high-tech industries : the case of the ASIC industry. [online] Disponível na
Internet via WWW.URL: http:// www.unimaas.nl/ document/ fdewb.htm. Netherlands Institute of Business Organization and Strategy Research, University of Maastricht, Dec. 1997.

WILLIAMSON, O. E.

Markets as hierarchies : analysis and antitrust implications. New York : The Free Press, 1975.

The economic institutions of capitalism. New York: The Free Press, 1985.

YOSHINO, M. Y.;

RANGAN, U. S.

Strategic alliances : an entrepreneurial approach to globalization. Boston, MA : Harvard Business School Press, 1995. 